\title{
Garment, or upper-garment? A matter of interpretation?
}

Eva $\mathrm{Ng}$

The University of Hong Kong, Hong Kong

nsng@hku.hk

\begin{abstract}
In an adversarial common-law courtroom, where one party tries to defeat the other by using words as weapons, polysemous words more often than not pose a problem to the court interpreter. Unlike in dyadic communication, where ambiguity can be easily clarified with the speaker by the hearer, court interpreters' freedom to clarify with speakers is to a large extent restricted by their code of ethics. Interpreters therefore can only rely on the context for disambiguating polysemous words. This study illustrates the problem of polysemy in an interpreter-mediated rape trial. It exemplifies how the interpreter's goal to avoid contradictions by making her interpretation of a polysemous word consistent with the preceding context runs counter to that of the bilingual cross-examiner, whose primary goal is to identify inconsistencies in the hostile witness's testimony in order to discredit him. This study also manifests a denial of the interpreter's latitude in the interpretation of contextual clues and her loss of power in a courtroom with the presence of other bilinguals.
\end{abstract}

Keywords: $\quad$ POLYSEMY; AMBIGUITY; CONTEXT; INTERPRETING; BILINGUALS

\section{Introduction}

\subsection{The bilingual Hong Kong courtroom}

From 1842, when Britain began its colonial rule over Hong Kong, until 1974, when Chinese was given official status in Hong Kong, English was the only official language and trials in all courts were conducted in English. In a trial conducted in English, court interpreting is a sine qua non, as witnesses and defendants involved in trial proceedings are predominantly Cantonese-speaking. These lay-participants are either monolingual, or not sufficiently confident to testify in English, which for most of them is only a language they learned at school and may have used at work. The liberty to use Chinese in all courts after the changeover of Hong Kong's sovereignty in 1997 has resulted in an increasing use of Chinese (i.e. Cantonese) for trial hearings over the past decade, especially in lower courts. In the High Court however English remains the dominant language (see E. $\mathrm{Ng}, 2009$ ). Statistics from the Department of Justice show that in 2009 over two thirds of the criminal trials in the Court of First Instance of the High Court and almost half in the District Court were still conducted in English, though Magistrates' Court cases were mostly heard in Cantonese' ${ }^{1}$. Hong Kong is therefore, as K. H. Ng (2009: 120) puts it, "one of the most "interpreted" legal systems in the world' and ironically, unlike in most other jurisdictions, court interpreters are hired to serve not the linguistic minorities, but the linguistic majority (E. Ng, 1997; K. H. Ng, 2009: 120).

\footnotetext{
${ }^{1}$ Percentage of criminal cases conducted in Chinese in 2009:

Court of First Instance-26.1\%; District Court-55.5\%; Magistrates' Courts-84.5\%

(Source: Department of Justice, HKSAR)
} 


\subsection{Power of the interpreter}

In an interpreted encounter, where the interpreter is the only bilingual, s/he is cast in a highly important role in facilitating a communicative act among the monolingual interlocutors, who otherwise would not be able to interact with one another. Anderson (2002) suggests that the interpreter's position in the middle 'has the advantage of power inherent in all positions which control scarce resources'. This advantage allows interpreters considerable latitude in defining their own behaviour and greater control over the interaction, and to translate selectively, while their monolingual clients are not able to ascertain the difference unless they overstep 'rather wide bounds' (2002: 212 - 213).

In the bilingual Hong Kong courtroom however, interpreters do not enjoy this inherent power because the chance of working with bilingual legal personnel and even bilingual lay-participants is high. This inevitably subjects the interpreters to external pressure as their performance is scrutinised throughout the trial by the bilinguals, who can always comment on or even challenge their interpretation. In other words, the power of the interpreter in the Hong Kong courtroom is considerably reduced, as Anderson expresses it, 'the power of the interpreter disappears, if a client happens to be bilingual' (2002: 214). In case of a dispute over the interpretation of a single word or an expression, the bilingual legal professional, being a powerful participant in the courtroom, always has an upper hand over the interpreter as I will demonstrate with my data below.

\subsection{Language in the adversarial courtroom}

The adversarial common-law courtroom relies heavily on the oral presentation of evidence. There is therefore a metaphor of the trial as a war of words, where opposing parties try to defeat each other by using language as their weapons (Maley \& Fahey, 1991: 3), and 'in which only one side will win' (Danet, 1980: 190). Language is the medium through which competing versions of the same reality are constructed and presented to an impartial audience, i.e. a jury or a judge. While the prosecution tries to construct a story that will prove the guilt of the accused, the defence strives to present one that will at least create a reasonable doubt in the judge's or the jury's minds. The success or failure of the battle hinges to a large extent on how effectively language as a weapon is used by the parties. The strategic use of language thus becomes all-important, as Hale rightly points out, '[n]owhere does language play a more important role than in the adversarial courtroom' (1997: 201).

In her study of the O.J. Simpson trial, Cotterill (2003) illustrates how the attorneys employed strategic lexical choices in their attempts to orient the jury towards a particular perception of the trial events and personalities. The prosecution, through the use of words with negative prosodies and connotations such as 'encounter' and 'control', aimed to portray Simpson as an aggressive and violent wife-beater. The defence on the other hand strove to dismiss the alleged cycle of violence as mere 'incidents', 'domestic disputes', 'verbal debates' and even 'conversations'. She suggests that 'through the skilful exploitation of different layers of lexical meaning, it is possible for lawyers to communicate subtle and partisan information about victims and alleged perpetrators' (2003: 67).

Danet's (1980) oft-cited study of a trial in a US court, where an obstetrician gynaecologist was charged with and later convicted of manslaughter in connection with a late abortion, best illustrates the power of language in the Anglo-American adversarial courtroom and the metaphor of the trial as a war of words. During the trial, the prosecution strategically referred to the result of pregnancy (RP) as 'baby', 'child' or 'person', which all carry the quality of aliveness and thus justify a manslaughter case. The defence on the other hand opted for terms such as 'foetus', 'embryo' or 'product of conception', which convey the notion that 
the RP was still inside the mother's uterus and was not alive in the full sense, and therefore the abortion could not have constituted the crime of manslaughter. Through the strategic use of language both sides aimed to persuade the jury to return a verdict in their favour. The conviction of the defendant shows that the prosecution succeeded in this war of words.

\subsection{Polysemy, ambiguity and context in court interpreting}

Polysemy refers to the association of one word with multiple meanings. The particular meaning of a polysemous word needs to be decided by the context in which it occurs. Polysemous words can be problematic in the courtroom as opposing parties attempt to arrive at meanings favourable to their case, especially when more than one meaning is possible in a particular context or due to a lack of context. In other words, the very nature of polysemy means that contextual ambiguity is often an inevitable result. Danet points out that ambiguity about the meaning of events is part of our everyday life, but ' $[\mathrm{w}]$ hat makes the legal process an especially attractive setting in which to study this problem is that in the law, decisions must be made' [italics hers] (1980: 190).

In dyadic monolingual communication, contextual ambiguity can be easily clarified, although in the adversarial courtroom, counsel for the opposing side may sometimes want to leave intact a piece of ambiguous information in a witness's testimony. Court interpreters however, bound by their professional ethics, cannot freely clarify with the speaker about the intended meaning of an ambiguous utterance as interlocutors in a dyadic monolingual communication usually do. Moreover, the use of 'short consecutive' as the norm in legal interpreting (De Jongh, 1992: 38), whereby the interpreter works with relatively short chunks of information at each turn, means that the contextual information available to the interpreter in court examination is, 'limited to the local context unfolding at each turn' (Lee, 2009: 94), or what Hatim and Mason (1997: 50) refer to as the 'local cohesion' covering no more than two or three sentences. Hatim and Mason suggest that to overcome this limitation, liaison interpreters, (a term which includes court interpreters), 'resort to a more readily accessible strand of textuality' or what they later refer to as 'context' (1997: 50). This means that court interpreters, like other liaison interpreters, have to rely heavily on the local linguistic context for their interpretation of an ambiguous utterance. The contextual information available to the court interpreters is limited, not only because of the mode of interpreting used in court, but also because interpreters are often denied access to the case file to prepare in advance for the trial for reasons of confidentiality. It follows that interpreters do not have the same access to the contextual information of a trial as do the other participants in the court proceedings: the witnesses and the defendant have direct experience of the case at trial and have had their own (and presumably different) versions ready to tell the court; counsel must have familiarized themselves with all the details of the case before the trial starts; by contrast the interpreter is kept in the dark. That is to say, court interpreters often lack the means-clarification questioning and context-required for disambiguating an obscure item, which may prove detrimental to the accuracy of the interpreted evidence as exemplified by Kredens and Coulthard (forthcoming). In their example, a Polish interpreter had in a police interview erroneously interpreted the alleged rape victim's evidence about the defendant's penetration, in the absence of a prepositional phrase, as a marked oral penetration instead of an unmarked vaginal one. This is ostensibly a result of the interpreter's lack of contextual knowledge of the case and thus her need to rely on the local linguistic context, as well as her adherence to the ethical code by refraining from clarifying with the speaker. Had she been briefed on the details of the allegation before the interpreting took place, or had she taken the liberty to clarify the ambiguity with the speaker, the error would have been avoided. 
The notion of context is central in any interaction. Drew and Heritage (1992: 18) define context in interaction as both 'the immediately local configuration of preceding activity in which an utterance occurs' and the 'larger environment of activities within which that configuration is recognised to occur'. They suggest that utterances are doubly contextual in that they are both context-shaped and context-renewing because while the interpretation of an utterance is decided by the context in which it occurs, 'the current utterance will itself form the immediate context for some next action in a sequence...' (1992: 18).

Following Drew and Heritage, Ehrlich suggests that the question-answer sequences of a trial are illustrative of the doubly contextual nature of utterances, as a question in a question-answer sequence depends on previous utterances for its production and interpretation, and at the same time it shapes and constrains the utterance (the answer) that will follow (2001: 31). This is echoed by Janney who notes that 'interpretations of utterances depend on information provided by earlier utterances in the sequence and, at the same time, constitute information necessary for interpreting later utterances in it' (2002: 458). This suggests that interlocutors, whether in ordinary conversations or courtroom interactions, do benefit from earlier utterances in their interpretation of later, in particular, ambiguous utterances.

Interpreters working in the courtroom however do not enjoy the same degree of latitude as other participants in the proceedings do in their interpretation of contextual clues. The views that the interpreter should just translate, not interpret and that the role of the interpreter is to act as a mere conduit still prevail in the legal sphere (e.g. Hussein, 2011; Morris 1995), though empirical studies (e.g. Berk-Seligson, 1990; Hale, 2004; Roy, 2000; Wadensjö, 1998) have demonstrated to the contrary. All these studies reveal that interpreters play an active role in negotiating meaning with the primary participants and in making sense of what is said by them. When it comes to the interpretation of ambiguous words or expressions, the interpreter's decision to opt for one meaning rather than another based on the contextual clues may attract criticism from parties who decide that it would favour their case if the word were interpreted otherwise.

\section{Data and aims of the study}

This study represents a small portion of a larger research project on the reality of courtroom interpretation in Hong Kong. The data for the entire research project consists of recordings of 9 criminal trials from the three levels of courts in Hong Kong, namely, the Magistrates' Court, the District Court and the High Court, totaling over 100 hours of recording time ${ }^{2}$. The recordings were transcribed, following conventions for transcribing conversations (cf. Silverman, 2006), with information containing personal data changed or concealed in the transcript to ensure anonymity and confidentiality.

The present paper focuses on a High Court rape case, and aims to illustrate the problem of polysemy in an interpreter-mediated trial conducted in English and the divergent strategies adopted by the cross-examiner and the interpreter in the pursuit of their respective goals. In the case under discussion, both the Prosecution and the Defence Counsel are bilingual in English and Cantonese, but the judge speaks only English. The point at issue is

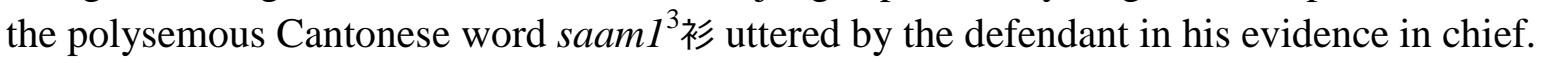

\footnotetext{
${ }^{2}$ I am indebted to the High Court Registrar of the Judiciary of Hong Kong for granting me access to the recordings of court proceedings, and the Leung Kau Kui Research and Teaching Endowment Fund of The University of Hong Kong for funding this project in part.

3 Romanisation of Cantonese characters in this study is based on Jutping, a Cantonese Romanisation system developed by the Linguistic Society of Hong Kong. This system distinguishes 6 tones in Cantonese and the number at the end of a syllable is a tone marker.
} 


\section{Analysis}

\subsection{Meanings of saam1}

The word saaml in Cantonese (or shān in Mandarin Chinese) is polysemous. The Chinese New Dictionary (Liu, 1993) gives two meanings to this Chinese character:

1. 單上衣 (upper garment);

2. 泛指衣服 (a generic reference for clothes).

In other words, saaml can be a generic term to refer to clothing/garment (usually used without a quantifier), or a more specific term, usually used with a quantifier gin6 件 (piece), to refer to a piece of clothing worn on the upper part of one's body (a shirt, a blouse, a jumper and even a jacket) - upper garment, which is how it is usually translated in the Hong Kong courtroom if it is understood in the latter sense. However the use of a quantifier alone does not serve as a clear-cut distinction between the meanings of this problematic word. For example, the expression ngo5 dong1 si4 mou5 zeok6 saaml我當時布着衫 (without the presence of a quantifier gin6) can be taken to mean BOTH 'I was not wearing any clothing at that time, i.e. being naked' AND 'I was not wearing any upper garment at that time'. In other words, the absence of gin6 does not automatically give the word a generic sense, and vice versa. For example, the utterance ngo5 jat1 gin6 saam1 doul mou5 maai5 dou3 我一件衫都布

買到 is usually understood to mean 'I didn't buy even a single piece of clothing' despite the presence of the quantifier gin6. The argument in this case lies in the interpretation of the meaning of this particular word in Cantonese.

\subsection{Prosecution case}

It is the prosecution's case that the victim, Miss M, was raped by the defendant in his home. Miss M, a lesbian, had been a cohabitant of the defendant's sister and had for over a year lived in the same premises where the defendant resided and where the alleged rape subsequently took place. On the day of the incident, Miss M's homosexual relationship with the defendant's sister had broken up and she had moved out of the flat, to which she returned to pack her belongings. At the material time no one was home except the defendant. According to Miss M, and the defendant's own evidence, the defendant was wearing only a pair of shorts prior to the sexual intercourse, without any clothing on the upper part of his body. Miss $\mathrm{M}$ was raped while she was lying on the top bed of a bunk for a nap after packing her belongings, and she could not resist the defendant's advance as she was weak and feeble at the material time. Miss $M$ did not report to the police immediately after the incident because she was confused, but talked to her friends before a report was finally made to the police.

\subsection{Defence case}

The defendant did not dispute having sex with Miss M, but alleged that the sexual intercourse was consensual. He elected to testify in the witness box and described in his evidence in chief how Miss M pulled his saaml while he was standing on the ladder of the bunk bed, which he took as an invitation for him to go up to the bed. He acted accordingly and had sex with her on the bed. The following extract from the transcript of his testimony in chief and its rendition by the interpreter contains his description of Miss M's pulling. (Words in italics are 
my transliterations/translations of the original Cantonese utterances or back-translations of the interpreter's Cantonese interpretation. See the abbreviations and transcription symbols used in this study in the Appendix.)

Extract 1: Examination-in-chief of Defendant

1. D 咁係同一時間:，(.)佢就： si: eh用佢嘅:左手就(.)少少彎彎 地，就拉住我件衫，啫係腰度件衫。

Then at the same time, (.)she si: eh slightly bent her left arm to pull my piece of garment/upper garment (gin6 saam1), that is, my piece of garment/upper garment (gin6 saam1)at the waist area.

2. I And then...你再講多一次。

And then...say that again.

3. D Er 佢用佢嘅左手拉我 er 腰度, 啫係腰部份嘅件衫。

She used her left hand to pull my waist area, that is, the garment...piece of garment/upper garment at my waist area.

4. I And then, she used her left hand to pull the um (.) garment at my eh waist area.

\subsection{The Interpreter's strategy}

Note that the quantifier 件gin6 is used before the word saaml by the defendant, which seems to suggest a more specific meaning of the word-upper garment. However, the interpreter's choice of the word 'garment' in her interpretation seems to be a well-deliberated decision, bearing in mind that it had been established in both Miss M's and the defendant's previous own testimony that the defendant was not wearing any 'upper garment' throughout the whole incident. The use of the word saaml with the quantifier gin6 by the defendant seems to take the interpreter by surprise. Her request in turn 2 for the answer to be repeated without first asking for the court's leave to do so may be regarded as a delaying tactic to buy her time as she searches for an English equivalent for the Cantonese word saam1. Note also the filler 'um' and the brief pause before she utters the word 'garment' in turn 4. Apparently, the interpreter, having gained the extra time from the defendant's repetition of his answer and a brief hesitation of her own, decides to opt for an interpretation consistent with the alleged victim's and the defendant's earlier evidence. In other words, the witness's and the defendant's earlier utterances have shaped her interpretation of the word in question. Her goal to strive for unity and consistency nonetheless goes against that of the cross-examiner.

\subsection{The cross-examiner's strategy}

In cross-examination, it is the goal of the examining counsel to discredit the hostile witness and hence the opposing side's version of events. The usual strategy is to identify inconsistencies or contradictions in the witness's testimony so as to create a reasonable doubt in the mind of the jury or the judge. It follows that when faced with a polysemous or an ambiguous word or expression in a witness's utterance, what the cross-examiner is after is an 
interpretation which will create contradictions or inconsistencies with the witness's earlier utterances.

The interpreter's rendition of saaml as 'garment', which has in effect removed a possible contradiction with the defendant's earlier utterances, was nonetheless not challenged by the prosecutor at this stage. It is possible that the prosecutor wanted to leave a reasonable doubt in the mind of the jurors, who were all English/Cantonese bilinguals, with Cantonese as their native language ${ }^{4}$ and would most likely rely on witnesses' testimony in Cantonese, rather than the interpreted version for their verdict. Challenging the interpreter's rendition in the defendant's evidence in chief would give the Defence Counsel an opportunity to clarify with the defendant over what he meant by his utterance of the word saam1, which would most likely result in the contextual ambiguity and hence a reasonable doubt being removed.

Instead, the prosecutor chooses to question the credibility of the defendant's testimony in his cross-examination of him by pointing out to him the contradiction in his evidence. In the following extract of the transcript, the prosecutor first gets the defendant to confirm that he was not wearing any upper garment during the whole event.

\section{Extract 2: Cross-examination of Defendant}

1. PC Alright. From the moment you opened the door for Miss M (.) until the sexual intercourse completed, nothing at the top.

2. I <Cantonese interpretation omitted for the sake of brevity>

3. $\mathrm{D}=$ 係。

$$
=y e s \text {. }
$$

4. I Yes.

Having got the defendant to confirm that he was not wearing any upper garment, the prosecutor proceeds to suggest that there was no such pulling by Miss $M$ as alleged by the defendant and accuses the defendant of fabricating a story favourable to him as illustrated in Extract 3 .

\section{Extract 3: Cross-examination of Defendant}

1. $\quad$ PC =Alright. Now, you have made up (.) a very good story about how (.) that day developed into your going up onto (.) her bed.

2. I <Cantonese interpretation omitted for the sake of brevity>

3. D 我布作到古仔, [我可以發誓。 I didn't make up a story.[I can swear.

4. I swear(.) by God.

[I didn't. I didn't eh make up any story. I can

\footnotetext{
${ }^{4}$ I witnessed the empanelling of the jury on the first day of this trial as I took my students to the High Court for a visit.
} 
5. PC There was only one hitch though. You were not wearing any upper garment that day.

6. I 咁但係呢, 有一點就係話當時呢, 你係有着到任何嘅上衫 個噃, 係咪呀?

But there is one thing, that is, you were not wearing any upper garment. Is that right?

7. D 係。

Right.

8. I Ya.

9. $\quad$ PC So, how could she have pulled (.) you by the upper garment (.) at the waist position?

10. I 咁佢當時又點樣係扯你㧽件上衫......係eh腰部嘅衫呀?

So how could she have pulled your upper garment...that is...eh...garment at the waist position?

Note that the Prosecution Counsel uses 'upper garment', in both turn 5 and turn 9, despite the interpreter's rendition of the word saaml as 'garment'. In the Cantonese interpretation in turns 6 and 10, the interpreter has to add the word soeng6上(upper) before saamlsoeng6saaml - to differentiate it from the more ambiguous word saaml and of course her rendition of it as 'garment'. However, since the actual word uttered by the defendant is saam1, not soeng6saam1, the interpreter must have realised the need to reconcile the discrepancy in her Cantonese interpretation in turn 10 when she hesitates after rendering 'upper garment' as soeng6saaml and finally settles on saaml, in an obvious attempt to make her interpretation consistent with the actual word used by the defendant, and presumably her interpretation of it as 'garment' as well. It must also be noted that the term soeng6saaml is marked and not an ordinary or idiomatic expression.

The prosecutor's challenge of the defendant's evidence has now necessitated the expatriate judge's review of his notes. The judge, being monolingual in this context, can only follow the testimony based on the English interpretation. As the interpreter has rendered saaml as 'garment', not 'upper garment', his notes show no inconsistency in the defendant's testimony. The following extract demonstrates the discussion between counsel and the judge in this regard. 
Extract 4: Interaction between Judge and Counsel

1. J Now, the question is, did he say she pulled him by the shorts, or at the waist area. (19) Well, my note reads 'she used her left hand to pull my garmenT(.) [at the waist area'.

2. DC [Yea.

3. PC [Yes, I have got the Chinese as well, (.) My Lord.

4. DC 'garment', he said.

5. J 'Garment', (.) not 'upper garment'.

The prosecutor however points out in Extract 5 below that the word 'garment' is the translation of the interpreter, whereas the word from the mouth of the defendant is saaml, which he has understood to be 'upper garment'. This subsequently leads to the playback of the recordings.

\section{Extract 5: Interaction between Judge and Prosecution Counsel}

1. $\quad$ PC It was...it was...the Chinese was saam1. One can (.) play back the video...the...the digital (.) recording. Although 'garment' was the word er used by the lady interpreter, the Chinese out of the mouth of the witness was saaml, which means 'upper garment'.

2. J (12) Er well, better listen to this.

In his later argument, the prosecutor also mentions the use of 'upper garment' by the Defence Counsel in his follow-up question to the defendant regarding the alleged pulling by Miss $\mathrm{M}$, which the prosecutor suggests is indicia that the word saaml uttered by the defendant is also understood by the Defence Counsel, as a Cantonese speaker himself, to mean 'upper garment'. Here is the follow-up question by the Defence Counsel in the examination-in-chief earlier on.

\section{Extract 6: Examination-in-chief of Defendant}

1. DC Now, when...when she used the hands to touch or drag...pull your...your... your garment, upper garment, at the waist-le... area, did you treat as invitation from her to (.)to up to the bed?

2. I 嗱, 當佢呢, 係用隻手呀去...去扯你er哩一個腰咽件......er湢個 祄...咽啲嘅衣物嘅時候呢，你::係咪er視佢哩個動作呢，作為係 一個邀請呀?

Now, when she used her hand to pull...pull your ...uh ...piece...uh that one garment...those clothing at the waist area, did you:: take that as an invitation? 
A closer look at the transcript, however shows that the Defence Counsel starts off by using the word 'garment' before switching to 'upper garment', which in a way demonstrates his own indecisiveness over the meaning of this word.

As in Extract 3, the interpreter seems to have a problem with the Defence Counsel's use of the term 'upper garment', which after all is not her rendition of the defendant's utterance of saam1. She is first observed to use the quantifier 'piece' (gin6, which as mentioned above, would tend to give saaml a meaning of 'upper garment'). Following a brief hesitation, she changes to use another quantifier 'one' (go3), which is however not an appropriate quantifier to collocate with saaml, before settling on 'those' (go2dilge3) followed by a generic term 'clothing' (jilmat6) she has finally come up to replace the ambiguous word saaml. Her move again can be regarded as an effort to strive for consistency in her interpretation of the defendant's utterance of 'saam1' as 'garment'. Following the playback of the recordings, the judge summarises the evidence in Extract 7.

\section{Extract 7: Interaction between Judge and Defence Counsel}

1. J My interpreter interpreted it as 'garment' in English, [not 'upper (.) garment'.

2. DC [Yes, yes.

3. J But, he did use the word saam1.

4. DC Yes.

5. J Em (.) when you asked him (.) the follow-up question, (.) you (.) said 'garment', ['upper garment'=

6. DC

[first.

In the following extract, the prosecutor goes on to suggest that the translation of saaml as 'garment' by the interpreter is not accurate, citing the defence counsel's reference to it as 'upper garment' in his follow-up question to reinforce his argument.

\section{Extract 8: Interaction between Judge and Prosecution Counsel}

1. PC Saaml, the Chinese used by the accused himself was saaml, and it was translated (.) as 'garment'=

2. $\mathbf{J}=$ Yes, you say that the translation is incorrect. It should be 'upper garment'?

3. PC To be er...to be exact, it should be 'upper garment'. But, Mr. W somehow got the point and asked the question by using the word 'upper garment'

\subsection{The interpreter's dilemma}

Now the time has come for the interpreter to be confronted with a misinterpretation allegation. This inevitably places the interpreter in a dilemma: adopting the suggestion of the 
prosecutor is tantamount to the confession of an interpretation error, whereas insisting on her earlier interpretation would for sure spark further heated discussion and would most likely attract criticism or even hostility from the prosecutor. The former would entail a loss of face on the part of the interpreter while the latter would obviously be seen as a confrontation to the authority, neither of which seems to be an easy way out for the interpreter. In any case, a decision has to be made. In this case, since the judge does not speak Cantonese, he cannot act as a referee and therefore has to leave the matter entirely in the hands of the interpreter as indicated in turn 1 of Extract 9. The interpreter's response in turn 2 is ambiguous and has led the judge to believe that she would leave the interpretation as just 'garment' (turn 3). The judge seems to be taken aback by the interpreter's decision to adopt the prosecutor's suggestion and there is also a tone of resignation in his utterance in turn 5.

\section{Extract 9: Interaction between Judge and Court Interpreter}

1. J (7) Well, I suppose insofar as the first one is concerned, the question is whether my interpreter is happy with the interpretation she's uh...she's given, or whether she wants to er qualify that in any way.

2. I < in a low voice >Yeah, I am happy with that=

3. $\mathrm{J}=$ You are happy with interpretation just 'garment'?

4. I Er with er 'upper'.

5. J 'upper garment', okay. < sighing $>$ Right

Now having successfully established that saaml equates with 'upper garment', the prosecutor goes on to suggest to the defendant that since he was not wearing any upper garment at the material time, there was no such pulling by the victim and that the alleged invitation from her is a story invented by the defendant.

\subsection{Re-examination by Defence Counsel}

Seeing that the defendant's evidence has been attacked by the Prosecution Counsel for want of consistency, which could be potentially damaging to the defence case, the Defence Counsel makes use of the re-examination process to give the defendant an opportunity to account for the contradiction. In Extract 10 below, the Defence Counsel tries to clarify with the defendant what he means by his utterance of the very word saaml.

\section{Extract 10: Re-examination of Defendant}

1. DC Now, but, when you said in the evidence, which is recorded, ‘腰部'<jiul bou6-waist area >...'腰部嘅衫' < jiul bou6 ge3 saam1-garment/upper garment at the waist area >, (.) what...what do you mean by that?

2. I <Cantonese interpretation omitted for the sake of brevity> 
3. D 啫係講緊(.)橡筋㧽個位, [er:

Talking about the elastic band area, er:

4. I

[Er what I meant was that the

elastic er area

5. DC Area of what?

6. I <Cantonese interpretation omitted for the sake of brevity>

7. D Er褲㧽橡筋㧽個位。

Elastic band of the shorts/trousers.

8. I That is the elastic of (.) the shorts area.

9. DC You mean the band of the...of the shorts?

10. I <Cantonese interpretation omitted for the sake of brevity>

11. D 係。

Yes.

Notice the omission of the quantifier gin6 by the Defence Counsel in his quotation of the defendant's earlier testimony. In turn 1, Extract 1, the defendant says '我件祄，啫係腰度件衫' (ngo5 gin6 saam1, zek1 hai6 jiul dou6 gin6 saam1-my piece of garment/upper garment, that is, the piece of garment/upper garment at the waist area), with the placing of the quantifier gin6 before saaml in two places in his initial utterance. When asked by the court interpreter to repeat his answer, the defendant says in turn 3 of the same extract '腰部份蔇件衫' (jiul bou6 fan6 ge3 gin6 saam1 - the garment...piece of garment/upper garment at the waist area) as an elaboration of his answer in turn 1, which again includes gin6 before the word saaml. However, this utterance is not grammatical, with the insertion of the possessive particle ge3 before gin6 as ge3 and gin6 are syntactically redundant and semantically mutually exclusive. As has been pointed out earlier, the use of gin6 before saaml in this context tends to give saaml a more specific sense. By contrast, the use of ge 3 before saaml is likely to make it a generic reference. It seems that the utterance of $g e 3$ by the defendant in the first place is a slip of the tongue, which he has then corrected to gin6.

Now the Defence Counsel must have realised the damaging effect that the use of gin6 might have on the credibility of the defendant when he quotes the defendant's earlier testimony with this word omitted. This has the effect of rationalising the defendant's subsequent explanation about his intended meaning of saaml.

\section{Conclusion}

This study has sought to illustrate the metaphor of the trial in the adversarial courtroom as a battle of words and to demonstrate the problem of polysemy in an interpreter-mediated trial. It exemplifies how the interpreter's aim to avoid contradictions by making her interpretation of a polysemous word consistent with the preceding context runs counter to that of the crossexaminer, whose primary goal is to identify inconsistencies in the hostile witness's testimony 
in order to discredit him.

Meanwhile, this study manifests the external pressure the interpreter is subjected to and a loss of power on the part of the interpreter in the encounter when the interlocutor(s) happen(s) to be bilingual as suggested by Anderson (2002). In the case under study, the bilingual skill of the examining counsel has empowered and enabled him to challenge and 'correct' the interpreter's interpretation of the ambiguous utterance to suit his purpose. The interpreter, on the other hand, has seen her power as a communicator in the encounter diminished by the bilingual counsel and her latitude to interpret an ambiguous utterance based on earlier utterances is obviously restrained; she is, as Fenton (1997: 30) puts it, characterised as someone who is not supposed to 'take an intelligent, thinking interest in the proceedings'. The study also exemplifies the dilemma the court interpreter is faced with when the accuracy of her interpretation is called in question. Her concession may also be regarded as a submission to the power in court, where the power asymmetry between lay-participants and legal professionals is palpable.

\section{Appendix: Abbreviations and transcription symbols}

Abbreviations

J=Judge $\quad \mathrm{I}=$ Interpreter $\quad \mathrm{D}=$ Defendant $\quad \mathrm{DC}=$ Defence Counsel

$\mathrm{PC}=$ Prosecution Counsel $\quad \mathrm{W}=$ Witness

\section{Transcription symbols}

$=\quad$ latched utterances, with no pause between the end of one utterance and the start of the next (i.e. no pause between turns)

: a colon indicates prolongation of the immediately prior sound. The length of the row of colons indicates the length of the prolongation.

$\langle\quad$ angle brackets contain transcriber's descriptions rather than transcriptions.

(2) a number in parentheses indicates the length of a pause in seconds

(.) a dot in parentheses indicates a brief pause of less than a second.

[ left square brackets indicate the start of an interruption and the utterance which is interrupted

boldface words in boldface represent elements under discussion in this paper

CAPS words in capital letters indicate a louder voice relative to the adjacent talk

Italics words in italics are the author's transliterations/translations of Chinese utterances/back-translation of the interpreter's Chinese rendition

\section{References}

Anderson, R. B. (1976/2002) Perspectives on the role of interpreter. In F. Pöchhacker and M. Shlesinger (eds) The Interpreting Studies Reader. London/New York: Routledge.

Atkinson, J. M. and Drew, P. (1979) Order in Court: The Organisation of Verbal Interaction in Judicial Settings. Atlantic Highlands, N.J.: Humanities Press. 
Berk-Seligson, S. (1990) The Bilingual Courtroom: Court Interpreters in the Judicial Process. Chicago: University of Chicago Press.

Cotterill, J. (2003) Language and Power in Court. New York: Palgrave Macmillan.

Danet, B. (1980) 'Baby' or 'fetus'?: language and the construction of reality in a manslaughter trial. Semiotica 32(3-4): 187-220.

De Jongh, E. M. (1992). An Introduction to Court Interpreting: Theory \& Practice. Lanham, Md.: University Press of America.

Drew, P. and Heritage, J. (1992) Analyzing talk at work: an introduction. In P. Drew and J. Heritage (eds) Talk at Work: Interaction in Institutional Settings. Cambridge: Cambridge University Press: $3-65$.

Ehrlich, S. (2001) Representing Rape: Language and Sexual Consent. London/New York: Routledge.

Fenton, S. (1997) The role of the interpreter in the adversarial courtroom. In S. E. Carr, R.P. Roberts, A. Dufour, and D. Steyn (eds) The Critical Link: Interpreters in the Community. Amsterdam: John Benjamins Pub. Co, 29-34.

Hale, S. (1997) The interpreter on trial: pragmatics in court interpreting. In S. E. Carr, R.P. Roberts, A. Dufour, and D. Steyn (eds) The Critical Link: Interpreters in the Community. Amsterdam: John Benjamins Pub. Co, 201-210.

Hale, S. (2004) The Discourse of Court Interpreting: Discourse Practices of the Law, the Witness, and the Interpreter. Amsterdam/Philadelphia: John Benjamins Pub. Co.

Hatim, B. and Mason, I. (1997) The Translator as Communicator. London/New York: Routledge.

Hussein, N. M. A. (2011) Legal Interpreting in the Criminal System: An Exploratory Study. Unpublished PhD thesis. De Montfort University.

Janney, R. W. (2002) Context as context: vague answers in court. Language and Communication 22: 437-456.

Kredens, K. and Coulthard, M. (forthcoming) Corpus linguistics in authorship identification. In P. Tiersma and L. Solan (eds) The Oxford Handbook of Language and Law.

Lee, J. (2009) Interpreting inexplicit language during courtroom examination. Applied Linguistics 30(1): 93-114.

Liu, B. (Ed.) (1993) New Chinese Dictionary (Zhonghua Xin Cidian 中華新詞典). Hong Kong: Chung Hwa Book Co.

Maley, Y. and Fahey, R. (1991) Presenting the evidence: constructions of reality in court. International Journal for the Semiotics of Law 4(10): 3-17. 
Ng, E. (1997) The Role of the Court Interpreter. Unpublished M.A., University of Birmingham, Birmingham.

$\mathrm{Ng}$, E. (2009) The tension between adequacy and acceptability in legal interpreting and translation. In S. Hale, U. Ozolins \& L. Stern (eds) The Critical Link 5: Quality Interpreting - A Shared Responsibility. Amsterdam: John Benjamins Pub. Co., 3754.

Ng, K. H. (2009) The Common Law in Two Voices: Language, Law, and the Postcolonial Dilemma in Hong Kong. Stanford, Calif.: Stanford University Press.

Roy, C. B. (2000) Interpreting as a Discourse Process. New York: Oxford University Press.

Silverman, D. (2006) Interpreting Qualitative Data: Methods for Analyzing Talk, Text, and Interaction (3rd ed.). London; Thousand Oaks, Calif.: SAGE Publications.

Wadensjö, C. (1998) Interpreting as Interaction. London; New York: Longman. 